\title{
Aprendizagem da atenção: uma abertura à invenção
}

\author{
Maria Helena De-Nardin \\ Regina Sordi
}

\begin{abstract}
Resumo
O presente trabalho decorre de uma pesquisa sobre a atenção em sala de aula realizada com alunos e professores de duas turmas de primeira série do ensino fundamental. Foram realizadas aproximadamente cem observações, com notas de campo e gravações dos diálogos que se desenrolaram entre alunos e professores e a metodologia de análise do material foi qualitativa. Tais diálogos foram analisados, posteriormente, com o propósito de identificar breakdowns. Estes foram definidos como modulações da atenção expressas através de falas e gestos que apontavam para uma aparente ruptura do foco atencional, revelando um desvio do trabalho recognitivo em questão. O resultado das análises apontou para a predominância de duas modalidades distintas de atuação da professora diante do encontro com os breakdowns, sugerindo, como conclusão da pesquisa, que a atenção pode ser efeito da aprendizagem quando o ambiente, criado por aqueles que ensinam, tem o propósito de que todos possam acercar-se, o mais possível, de um sentido compartilhado de comunicação, caracterizando-a por uma autêntica relação de cooperação.
\end{abstract}

Palavras-chave: Aprendizagem, atenção, invenção.

\section{Attention learning: an opening to invention}

\begin{abstract}
This paper derives from a research project on attention in classroom. The work was carried out with teachers and students of two classes of the first grade of fundamental school. We achieved approximately one hundred observations with notes fields and recordings of the dialogues that happened among students and teachers. The methodology of analysis we used was qualitative research. The dialogues were analyzed with the purpose of identifying the breakdowns. They were defined as modulations of attention expressed through the speeches and gestures that pointed to an apparent rupture of the attentive focus revealing a detour of the recognition focus. The results of analysis pointed to a predominance of two different modalities of attention of the teacher concerning the breakdowns, suggesting as conclusion that attention can affect learning when classroom environment is perceived within a sense of communication and authentic relation of co-operation.
\end{abstract}

Keywords: Learning, attention, invention.

\section{Resumen}

\section{Aprendizaje de la atención: una abertura a la invención}

El presente trabajo resulta de una investigación sobre la atención en salón de clase realizada con alumnos y profesores de dos grupos de primer grado de la enseñanza primaria. Fueron realizadas aproximadamente cien observaciones, con notas de campo y grabaciones de los diálogos que ocurrieron entre alumnos y profesores y la metodología de análisis del material fue cualitativa. Estos diálogos fueron analizados, posteriormente, con la finalidad de identificar breakdowns. Estos fueron definidos como modulaciones de la atención expresadas por medio de intervenciones orales y gestos que señalaban una aparente ruptura del foco de atención, revelando un desvío del trabajo recognitivo en cuestión. El resultado de los análisis mostró la predominancia de dos modalidades distintas de actuación de la profesora al encontrarse con breakdowns, sugiriendo, como conclusión de la investigación, que la atención puede ser efecto del aprendizaje cuando el ambiente, creado por aquellos que enseñan, tiene el propósito de que todos puedan acercarse, lo máximo posible, de un sentido compartido de comunicación, caracterizándola como una auténtica relación de co-operación.

Palabras-clave: Aprendizaje, atención, invención. 


\section{Introdução}

Quando nos referimos à atenção no âmbito escolar, na maioria das vezes, o termo vem associado ao Transtorno de Déficit de Atenção e Hiperatividade (TDA/H) que, a partir dos anos 90 , começou a obter importante prestígio nos meios médicos e nas escolas, chegando às famílias. A dificuldade em manter o foco de vigilância em tarefas escolares, o baixo rendimento, a inquietude motora, a impulsividade e o comportamento hiperativo são algumas das características propostas pelo DSM IV (1994), que devem ser evidenciadas em mais de uma situação social. Tais sintomas sustentam uma concepção com ênfase no adoecimento do indivíduo, cujos distúrbios podem ter causas múltiplas: tanto da ordem do desenvolvimento ou da estruturação orgânica, quanto da ordem do emocional ou relacional. São causas de caráter individual, avaliadas a partir de uma abordagem psicológica e epidemiológica constitutivas de um domínio da realidade no qual a cognição é entendida como capacidade de solucionar problemas e a atenção, por sua vez, tem papel específico: o controle do comportamento e a realização de tarefas. Compreendida como condição para a aprendizagem, sua análise restringe-se a uma atenção voltada para a captação e busca de informações (Kastrup, 2004). Nesta lógica, os sujeitos com queixas de falta de atenção são normalmente situados num quadro de patologia, em que o adoecimento é produzido no indivíduo e pelo indivíduo. Diante desse quadro, há uma questão ética e política que nos convoca a estabelecer relações com outros saberes, tais como os estudos da subjetividade e os estudos que tratam da cognição como processo de invenção com o objetivo de buscar outras formas de entender a capacidade atencional de crianças, adolescentes e adultos que, cada vez mais, são tomados como sujeitos disfuncionais, excessivamente agitados e com falta de atenção.

Não é nosso propósito entrar na discussão dos diagnósticos de déficit de atenção, mas promover uma discussão que contemple a complexidade de questões que envolvem o fenômeno atencional e que são da ordem do biológico, do fisiológico, do psicológico e do cultural. Neste contexto múltiplo, algumas características específicas da atenção vêm se revelando efeito de uma construção resultante de um modo de vida contemporâneo. Estudos mais recentes (Corea \& Lewkowiz, 2005; Crary, 1999; Kastrup, 2004) apontam para o fato de que os modos como ouvimos, olhamos ou nos concentramos em qualquer coisa têm um caráter profundamente histórico, o que nos permite pensar que nossa maneira de estarmos atentos não é ditada pela biologia ou por algum fenômeno imediato, mas é mediada por nossas experiências intra e intersubjetivas.

Seguindo essa perspectiva, o presente artigo baseiase em duas afirmações: a) um estudo da atenção em sala de aula conduz à necessidade de tratá-la como uma peculiaridade humana que pode ser modulada a partir do contexto histórico, e b) a atenção pode ser compreendida antes como efeito de um processo de aprendizagem do que como condição para que a aprendizagem ocorra.
Enquanto em situações escolares o que se requer é uma atenção concentrada, detida e polarizada, necessária para o processo de aprendizagem, o que se observa no cenário diário da atualidade é que nossa atenção tem sido alvo de uma diversidade incalculável de apelos, situações e informações, gerando, muitas vezes, certa dificuldade de concentração. Esse funcionamento atual tem um caráter histórico e é nele que apoiamos nossa primeira afirmação, pois, para compreendê-lo, é preciso observar as transformações pelas quais têm passado a percepção e os regimes de atenção, cujos efeitos se revelam, segundo Crary (1999), nos modos de subjetivação contemporâneo.

Crary (1999) desenvolve esta ideia partindo da afirmação de que a forma como prestamos atenção a nós mesmos e ao mundo tem uma constituição histórica. Esta dimensão da atenção permite pensá-la como um dos aspectos dos processos cognitivos que se constituem a partir da experiência de subjetivação que também é histórica. Sendo assim, não existe um sujeito e tampouco uma atenção que sejam estáveis e que, por isso, atravessariam os tempos sendo sempre os mesmos. O sujeito atento modula-se a partir de um determinado contexto. Os grandes avanços tecnológicos da produção e reprodução de imagens, a complexificação da vida urbana, a aceleração dos deslocamentos e as indústrias culturais, além de uma complexa rede de práticas e discursos que vêm se articulando ao longo dos séculos XIX e XX, são responsáveis por grandes transformações no nosso modo de ser e de experimentar o mundo.

Crary (1999) mostra como a atenção foi, aos poucos, transformando-se no eixo da vida mental, naquilo que dá coesão à consciência, comanda o comportamento e organiza a experiência perceptiva do mundo, deixando para trás a primazia da consciência apontada nos trabalhos filosóficos, psicológicos e científicos. A concepção funcional da atenção veio ocupar o lugar daquela que atribuía à percepção a capacidade de alcançar a realidade tal como é. Sendo assim, para compreender a atenção, é preciso considerar os mecanismos fisiológicos da percepção e sua ligação com a ação motora. Desta forma, a atenção foi assumindo um caráter normativo na configuração das subjetividades modernas.

A atenção, então, começa a ser pensada "essencialmente como um problema moderno" (Crary, 1999), pois o contexto que agora produz novas fontes de estimulação, novos produtos e diferentes fluxos de informação em número cada vez mais crescente passou a exigir sujeitos altamente atentos para poderem se inserir nas novas formas de produção industrial e nos novos arranjos de trabalho. O observador que emerge no século XIX está inserido em um arranjo social marcado por um processo de industrialização acelerado, cuja tecnologia dos inventos óticos põe-se a serviço da produção de um espectador mais atento, que acaba por se ver imbricado crescentemente em um regime de atenção e distração recíprocas. O excesso de estimulação sensório-motora produz uma fragmentação da percepção do mundo ao mesmo tempo em que viabiliza a constituição de uma atenção volátil. 
Desde que os conceitos de visão, percepção e mesmo de cognição passaram a se ancorar num corpo em movimento, ele foi se tornando a superfície de inscrições das normas e valores da sociedade. Na escola, isto terá uma importante consequência, pois a durabilidade da atenção e a docilidade dos corpos se tornarão a forma de diagnosticar crianças como portadoras de Transtornos de Déficit de Atenção.

A lógica cultural capitalista exige que aceitemos como "natural" a mudança constante do foco da atenção. Diante de uma tela, por exemplo, deparamo-nos com práticas cotidianas saturadas de estímulos cuja intensidade não nos permite o exercício da concentração. Recebemos tanta informação que não chegamos a interiorizar ${ }^{1}$ nenhuma delas. Normalmente não olhamos a televisão concentrados na tela. Concentração não é requisito do discurso midiático. Seu requisito é focalização, isto é, mudança constante de foco que o ato de zapear ilustra muito bem. O que se constitui, então, é uma relação com essas práticas da ordem da dispersão, que nada mais é do que o efeito da hiperestimulação a que somos submetidos diariamente, que exige apenas exterioridade e descentramento.

Vejamos, agora, o que se requer num contexto escolar. Nesse contexto, precisamos ler, produzir escritos, contestar, calcular, responder a exames, avaliações, desempenhar um sem número de tarefas que exigem capacidade de memorização e de concentração. A memória, como bem assinala Corea e Lewkowicz (2005), "é uma condição essencial" para levar a cabo todas estas tarefas. Ela constituise também em "efeito das práticas pedagógicas". Para poder exercer todas estas operações, há necessidade de estar concentrado, ou seja, centrado em um ponto e distante de qualquer estímulo que interfira nessa "relação de intimidade" que o aluno estabelece com sua "consciência". Em termos práticos, estar concentrado implica também estar quieto em um lugar, sem se mover. Nas atividades pedagógicas, o reconhecimento atento tem hegemonia sobre a percepção. Sendo assim, quanto mais reduzidos os estímulos externos, tanto mais eficaz resulta a aprendizagem.

Entre um zapping e uma leitura há, certamente, uma diferença significativa de experiência do tempo. Quando lemos ou estudamos, experimentamos um determinado ritmo de temporalidade - cumulativo e evolutivo - no qual cada momento se constitui desde um momento anterior que Ihe dá sentido. Ao fazer referência à qualidade evolutiva do tempo, não se trata de pensá-lo apenas como um encadeamento em linha, mas de conexões possíveis entre passado, presente e futuro, numa certa espessura de tempo que nos permite estabelecer relações entre as experiências vividas. Quando assistimos à televisão, habitamos um tempo que é o da pontualidade, do aqui e agora. As imagens sucedem-se sem qualquer relação entre si, apenas seguemse umas às outras. As duas situações revelam diferentes

1 A palavra interiorizar está empregada, aqui, no sentido de tomar consciência de ou, conforme Bergson (1999), "reconhecer atentamente" a partir de elementos que podem ser recuperados pela memória. ritmos de temporalidade que, ao serem experimentados pelos sujeitos, caracterizam o próprio modo de se subjetivar, donde diferentes formas de atuação da atenção podem revelar-se.

É preciso assinalar que os distintos regimes atencionais descritos não são exclusividade de uma ou outra experiência. Quotidianamente, experimentamos situações diversas e ambivalentes: para obter um bom desempenho em todos os recantos da vida, nos é exigido certo grau de concentração nas atividades, ao mesmo tempo em que precisamos demonstrar capacidade e maleabilidade de trocar de foco de interesse quando assim nos for requerido. Instala-se aí uma crise da atenção em cujo quadro não podemos compreender a desatenção como desvio de estados naturais, mas precisamos entender ambas atenção e desatenção - como representando um continuum, na medida em que os imperativos sociais conduzem tanto a uma quanto a outra.

Num regime onde a atenção facilmente se desdobra em dispersão, constituem-se sujeitos muito ligados que, para poderem cumprir sua tarefa de consumidores e para terem aumentada sua capacidade de atenção para a realização de tarefas, precisam ser desligados. Chama a atenção de Crary (1999) e Fernández (2001) um grande contrassenso: a transformação da desatenção e da hiperatividade em doença é estimulada por uma cultura que depende de uma sobrecarga de estímulos sensórios, da busca incansável do sucesso, de uma disposição dos indivíduos para desviar o alvo de sua atenção e da celebração da mobilidade incessante.

Noqueconcerneàaprendizagem, estaécompreendida como capacidade para solucionar problemas e, no que diz respeito à atenção, a ênfase está colocada sobre seu papel no controle do comportamento e no desempenho de tarefas cognitivas. Sob esta perspectiva, a atenção é tomada como subsidiária da aprendizagem, estando a serviço da captação e da busca de informação (Kastrup, 2004). Em situações de falha nessa forma de atuação, a atenção fica colocada no lugar da falta, do déficit. É comum observar que tanto a dispersão quanto a distração são consideradas indesejáveis diante da possibilidade de fazer frente ao funcionamento da atenção que teima em fugir da tarefa. Todavia é importante diferenciá-las, pois produzem efeitos distintos no processo de cognição.

Para fazer tal diferenciação, recorreu-se ao conceito de reconhecimento de Bergson (1999). Em sua concepção, - mundo se compõe de um "conjunto de imagens" interligadas. Dentre elas, nosso corpo apresenta-se como uma "certa imagem determinada", considerada o centro da ação, que se conturba por leves variações e é "capaz de dividir-se entre várias ações possíveis numa resposta ao problema causado pelo mundo externo" (Bergson, 1999, p. 14). Este mesmo corpo - uma imagem privilegiada - que é capaz de provocar infinitas respostas, é também capaz de problematizar o conjunto das outras imagens. Ele é, portanto, um centro de criação, assim definido por sua capacidade problematizadora. 
A matéria, que Bergson (1999) define como um conjunto de imagens, ao ser remetida a uma "ação possível", constitui o processo de percepção, que se produz a partir dos detalhes de nossas experiências passadas, ou seja, a percepção é antes o efeito de nossas lembranças. Ela é sempre uma composição de memória, desejo, impressão do momento e antecipação.

Para reaver o passado no presente, lançamos mão do ato de "reconhecer" que se manifesta de diferentes modos, em acordo com a percepção presente do sujeito. Diante de uma provável diferença na maneira de reconhecer, Bergson (1999) distingue entre "reconhecimento automático" e "reconhecimento atento".

A característica principal do "reconhecimento automático" é a sua realização através de movimentos que prolongam a percepção para obter efeitos úteis. Põese em ação uma disposição para agir cujos mecanismos estão corporificados, isto é, são constituintes da estrutura do organismo, resultado da história de suas interações com o mundo, para serem reproduzidos sempre que necessário. Quando uma ação se segue a um estímulo sem nenhum tipo de intervenção do próprio sujeito, este se torna um processo automático que caracteriza grande parte dos nossos atos diários e tem muitos pontos em comum com o ato reflexo. Tal reconhecimento se produz a partir dos mecanismos de repetição que adquirem a condição de hábito e por isto determinam modos de agir que acompanham automaticamente nossa percepção das coisas, donde se produz o equilíbrio com o meio.

Este conceito bergsoniano inspira, aqui, a estabelecer uma relação deste com um modo de atenção recognitiva caracterizada pela atuação dos "esquemas de recognição" (Kastrup, 1999), cuja função primordial é contribuir para o reconhecimento dos objetos, isto é, para a captação de informações objetivas e para a adaptação do sujeito ao meio. Neste modo de atuação, o que prevalece é uma capacidade de focalização da atenção e não seria equivocado dizer que ela é responsável pelas aprendizagens de caráter prático e utilitário da vida.

Por outro lado, retomando Bergson (1999), no "reconhecimento atento", os movimentos produzidos pela percepção retornam ao mesmo objeto depois de uma fuga do foco. Ao lançar-se em direção às lembranças, o reconhecimento revela sua característica centrífuga: afastase do foco (centro) seguindo em direções múltiplas, de volta ao passado. Característica essa que cria um verdadeiro espaço para a problematização, ou seja, para a invenção de problemas.

O momento em que presente e passado se encontram para produzir um movimento novo, que não se confunde com aquele voltado para os imperativos da ação, é o momento que Bergson $(1999,2005)$ nomeia de "duração". Neste artigo, esse momento é compreendido como aquele de uma possível atenção distraída, pois se trata do momento em que a atenção deixa de ser uma atenção focada no objeto para flutuar entre as relações possíveis em diferentes tempos e espaços, mantendo um elo de ligação de sentido entre o que está acontecendo e experiências anteriores.

Entender a idéia bergsoniana de "reconhecimento atento" permite tratar do aspecto psicológico do processo atencional que se caracteriza pela constituição de um circuito da atenção, no qual ela, ao deixar o foco porque renuncia a perseguir o resultado útil da percepção presente, volta-se para o passado e ganha certa espessura temporal. Não é difícil nos depararmos com esta experiência durante uma leitura. Frequentemente nos encontramos paralisados, com o olhar distante, experimentando algo que, diante de uma tela da televisão, torna-se quase impossível.

O retorno ao objeto assume, então, a conotação de um "trabalho intelectual", em que a atenção implica uma "solidariedade entre o espírito e seu objeto". Desta solidariedade surge a possibilidade de invenção, pois o estado de distração, que é um momento de flutuação da atenção que pôde transitar em outro lugar, revela-se numa capacidade de concentração.

Quando uma experiência de dispersão acontece, a permanência no foco é mantida por um tempo muito reduzido, deslocando-se rapidamente para outro, seguindo indefinidamente, vagando de um a outro foco de forma linear e homogênea. Já na experiência de distração, a mente permanece no foco por um momento, segue seu curso ao encontro com o passado (distrai-se) para poder retornar, de modo atualizado, no momento seguinte, formando um circuito que se completa. O que fica valorizado é a experiência do momento, que é uma experiência intensa, pura, concentrada, que pode, por um lado, resultar em pensamento - um certo ganho reflexivo - e por outro, em pura afetação.

Desde esta perspectiva, a distração desloca-se da ordem do imediato e permite o fluxo entre tempos e cognições diferentes. É um momento em que acontecem movimentos mentais, de fluxos de ir e vir da mente que transita entre a memória das experiências vividas corporalmente com diferentes padrões de relações. A distração, por sua característica de mobilidade, constitui espaços para a invenção, para a problematização, para a potência da vida. Portanto, estar distraído não é da mesma ordem da dispersão, pois, embora a atenção em estado de distração esteja experimentando uma certa errância, há, entre ela e a tarefa em questão, uma relação que as põe em contato.

No que diz respeito à aprendizagem, tratam-se de dois movimentos distintos de um mesmo processo. No primeiro, as coisas se passam mecanicamente, sem exigir transformações do sistema. É a característica da "aprendizagem recognitiva" (Kastrup, 1999), importante e necessária, mas não suficiente para a invenção do novo. No segundo, um ato de "reconhecimento atento" possibilita a criação da novidade, pois, para completar o circuito, é indispensável a passagem pelo estado de concentração, cujos ingredientes oscilam entre focalização-distraçãoretorno ao objeto. É importante assinalar que não se trata de um retorno ao que era antes, mas de um retorno transformado, inventado, com um certo grau de novidade. 
É o momento constitutivo de uma "aprendizagem inventiva" (Kastrup, 1999).

Aqui encontramo-nos com a segunda afirmação na qual baseamos este artigo: a que diz respeito à possibilidade de compreender a atenção como efeito de um processo de aprendizagem. Partindo do pressuposto de que a atenção é modulada em determinado contexto, tal afirmação aponta para a importância de criar estratégias de organização de espaço, de dinâmicas interpessoais e de experiências pessoais que possam ativar os fenômenos que possibilitam um modo de atenção de caráter mais inventivo.

Ao estudar a cognição, Kastrup (1999) introduz o problema do tempo e do coletivo, ampliando seu conceito, que não se restringirá à inteligência ou à solução de problemas. A autora mostra que é sua natureza inventiva o que possibilitará pensar um sujeito capaz de "inventar a si e ao mundo", situando na atuação do sujeito a possibilidade de encontrar novas formas de conhecer, de pensar e de produzir outras configurações de mundo. Então, Kastrup (1999) propõe diferenciar recognição e invenção, que ocuparão lugares distintos, mas complementares no processo da cognição.

Diariamente, vivenciamos experiências de recognição. Elas nos permitem o reconhecimento dos objetos, de modo que possamos ter um bom desempenho diário diante das situações com as quais nos deparamos. Nossa capacidade de busca de solução para os problemas experimentados em determinado contexto fica assegurada graças a tais experiências. Entretanto, as experiências de aprendizagem recognitiva não podem explicar o surgimento da novidade. Para falar desta, Kastrup (1999), inspirada na linguagem bergsoniana, utiliza-se do termo "problematização". A autora mostra que a cognição inventiva começa com a invenção de um problema que, em última instância, "consiste numa problematização da subjetividade, uma exigência de criação" (1999, p. 101).

Segundo Kastrup (1999), o processo de invenção caracteriza-se pela imprevisibilidade e pela problematização. Dadas essas características, a atenção não poderá ser pensada apenas como um processo único e homogêneo, mas como um movimento que se modula em diferentes fluxos e por isto pode mostrar-se funcionando de formas distintas, além do ato de prestar atenção a tarefas, objetos ou situações externas.

Quando se observam as dinâmicas em sala de aula, frequentemente, verifica-se que elas estão apoiadas em uma perspectiva que associa aprender à exigência de adaptação a um mundo pré-existente (Sordi, 1999), de modo que o ato de ensinar fica resumido a uma transmissão de conhecimentos acumulados historicamente que, sem dúvida, são importantes, mas não suficientes. A partir desse pressuposto, a atenção focalizada surge como condição fundamental para a aprendizagem, pois, quanto maior o poder de manter o foco em determinado objeto, maiores as chances de sucesso infantil. Neste caso, o ato de prestar atenção fica associado aos processos recognitivos como sua condição indispensável. Entretanto, conforme se vem mostrando, este modo de entender o fenômeno atencional limita-o ao processo de focalização, que não deve ser confundido com concentração.

$\mathrm{Na}$ perspectiva recognitiva de aprendizagem, necessariamente, não está implicada uma concentração, pois esta supõe a possibilidade de ir além da capacidade de executar tarefas; supõe uma possibilidade inventiva e, portanto, uma cognição enquanto capacidade problematizadora. Neste caso, a concentração, ao contrário do que normalmente se pensa, precisa recorrerà possibilidade de se distrair, sendo que o distrair-se é experimentado num "colapso", numa "rachadura" (Varela, 2003), ou ainda num momento de "descontinuidade" (Bergson, 2005). O sujeito experimenta um movimento de abertura necessário à invenção e que se revela como distração, que lhe possibilita transitar entre atenção e desatenção. Ao desatender do foco, dá-se um encontro entre o passado inteiro que acompanha o sujeito e o instante presente.

Isto posto, entende-se que, subjacente ao apelo de prestar atenção da escola, está um conceito que faz referência a um movimento de detenção, de fixação do foco, não de uma capacidade de concentração. Na escola, no trabalho, em frente ao computador ou à televisão ou em outras tarefas diárias, nossa atuação normalmente é de uma atenção focalizada, pois precisamos tratar de reconhecer o que se passa para poder executar bem as tarefas.

Assim, se de um lado lidamos com um conceito atual de atenção que a define enquanto um elemento necessário para o reconhecimento da informação, de outro lado, encontramo-nos com os estudos da consciência que apontam para outra perspectiva: a atenção que emerge como um estado possível e necessário para a invenção é uma atenção que transita entre estados de atenção focalizada e atenção distraída, que se trata de constelação de experiências e práticas, muito mais que uma questão de fixação, de olhar ou de sujeito como espectador.

\section{Método}

A análise da pesquisa desenvolveu-se a partir da reflexão sobre alguns protocolos destacados dentre uma série de aproximadamente cem observações dirigidas às relações aluno-professor-objeto do conhecimento. Participaram da pesquisa duas turmas de primeira série do ensino fundamental, sendo cada uma delas em escolas distintas. A escolha das escolas não obedeceu ao critério ensino público/privado, mas levou em consideração, de um lado, o interesse da direção sobre o tema e, de outro, um conhecimento prévio da atuação pedagógica da professora.

A metodologia adotada tem raízes nas pesquisas de caráter qualitativo, com uma abordagem de inspiração etnográfica. Os instrumentos utilizados foram notas de campo, áudio-gravações, registros dos diálogos e depoimentos espontâneos de alunos e professoras.

O problema formulado na etapa de observações foi: Como investigar as formas de atenção em sala de aula e suas relações com a aprendizagem? 
Para responder a tal pergunta, fez-se a opção pela análise dos indicativos de modulações da atenção que se denominou de sinalizadores. Os sinalizadores emergem de momentos de suspensão do foco atencional e foram identificados a partir das expressões verbais e gestuais dos sujeitos, tais como assinalamentos e questionamentos que apontavam para um aparente desvio do trabalho recognitivo em questão. Para nomeá-los, utilizou-se o termo breakdown (Varela, 2003), que aqui será definido como efeitos que se expressam na ação dos sujeitos frente a momentos de ruptura do foco atencional.

\section{Resultados e Discussão}

O resultado das análises apontou para a predominância de duas modalidades distintas de atuação da professora quando confrontada com os breakdowns e que foram classificados em dois subtipos: de um lado, o breakdown que acolheu a perturbação e resultou em momentos de problematização e, de outro, o breakdown que não acolheu a perturbação e resultou em momentos divergentes da problematização. subtipo.

Para exemplificar, tomemos um registro de cada

1) Breakdown que resulta em momentos de problematização: colapsos que articulam diversas situações sócio-cognitivas experienciadas pelos sujeitos, em sala de aula, e que são responsáveis pelo "lado autônomo e criativo da cognição" (Varela, 2003, p.78). São considerados os momentos de atenção inventiva.

Os recortes de alguns protocolos podem ilustrar tais experiências.

1.1 Cena das "mãozinhas": Após apresentar o desenho de um muro de tijolos sobre o qual se podia ver cinco pares de mãos, a professora propõe aos alunos: "Vamos imaginar que tem umas crianças escondidas atrás desse muro. Olhem as mãozinhas delas aqui. Eu quero saber quantas crianças estão escondidas. Mas, olhem só, isto não é suficiente. Eu quero saber como vocês pensaram pra descobrir isto".

Depois de se certificar de que as crianças haviam chegado a um consenso, a professora propôs que cada grupo revelasse como fizera tal descoberta. Ao ouvir a afirmação dos colegas de que havia cinco crianças atrás do muro e o relato de que sua descoberta fora feita contando as mãos de dois em dois, o aluno FE comentou: "Uma pessoa pode tá se segurando só com uma mão". Estava lançado um problema...

A problematização não fora apenas um mero movimento do menino. Algo no desenho (objeto) o forçou a problematizar. Inicialmente, FE deixou-se afetar pelo desenho e pelo que ele pôde representar. No momento seguinte, quando da apresentação de um grupo, FE revelouse procurando o sentido do que se mostrava entre o desenho e a fala dos colegas. Ao fazer essa procura, ele inventou um novo problema.
O desdobramento da cena promovido pela professora, que acolheu a fala de FE, acionou a sua própria capacidade criadora e das crianças: ela improvisou um muro-cartolina e propôs a dramatização da hipótese levantada por FE. A professora, ao se deixar tocar pela novidade proposta por seu aluno, que fugiu ao reconhecimento, promoveu um momento em que a comunicação foi adquirindo sentido a partir da coordenação de pontos de vista. Teve-se, a partir de então, uma experiência significativa de pensar sobre o pensamento de FE.

Vamos ao segundo subtipo de sinalizador:

2. Breakdown que resulta em momentos divergentes da problematização: colapsos que, ao emergirem das diversas situações sócio-cognitivas experienciadas pelos sujeitos, em sala de aula, não são acolhidas e promovem um retorno ao foco atencional e um não acolhimento da problematização.

2.1 Cena do "corpo humano": O objetivo da professora, quando propôs a atividade que segue, era estudar hábitos de higiene. Inicialmente, as crianças deveriam responder à pergunta "Pra que a gente usa..." (braço, pernas, mãos...). Nota-se que tal pergunta já pressupõe um não saber infantil, mesmo em se tratando do uso do próprio corpo.

A professora, então, questionou: "O mais importante, pra gente ficar bem, o que a gente precisa fazer? Ouviramse as mais variadas respostas, tais como: "tomar cuidado", "não correr", "comer". Diante dos muitos ensaios e erros das crianças que não responderam o que a professora esperava, ela deu-lhes uma pista: "quarta-feira vocês me falaram direitinho o que eu preciso pra ter um corpo saudável. Eu preciso hábitos. Que hábitos?". Finalmente, JO "descobriu" qual era a resposta esperada e falou "higiene".

Repetindo a afirmação da menina, a professora elaborou outra pergunta: "Quais são os hábitos de higiene pra manter o meu corpo saudável?”. Após um breve silêncio, RO respondeu: "Comer". A professora, então, questionou: "Comer é um hábito de higiene?", e RE acrescentou, na sequência, "Tomar banho". E assim as crianças seguiram enunciando hábitos de higiene, na tentativa de "entregar" à professora a resposta certa.

Quando a professora verbalizou o que desejava como resposta à sua pergunta "Quais são os hábitos de higiene pra manter o meu corpo saudável?", percebeu-se que um silêncio invadiu a sala. RO, revelando manter em suspensão aquilo que emergiu da sua experiência de breakdown, repetiu o que havia sugerido: "comer" (linha 2). Mas como pode "comer" preencher os requisitos da pergunta? Infelizmente, "comer", tanto quanto "correr" (atuações do corpo,) não têm a ver com os hábitos de higiene em que estava situada a atenção da professora. RO manteve sua atenção distraída na pergunta anterior (linha 1), o que parece ter produzido algum efeito no menino. Embora a professora desejasse ouvir algo alusivo aos hábitos de higiene, sua pergunta abria possibilidades 
para pensar muitas outras coisas. Mas, porque sua escuta estava focalizada nas respostas que preencheriam certos requisitos, a professora não conseguiu atender seus alunos, não conseguiu escutá-los, não conseguiu descentrar-se e por isso não acolheu o que diziam. Seu trabalho reduziuse a uma troca de informações que pretendia promover o encontro com respostas que preenchem os requisitos.

Nos exemplos transcritos, observa-se que o breakdown revelou-se como resultado da experiência de a) "suspensão do julgamento habitual", b) "redireção da atenção" e c) "deixar-vir". Estes três momentos fazem parte de um ciclo básico da "époché" e são qualificados por Depraz, Varela e Vermersch (2003) como experiência do sujeito em um determinado instante. Eles se entrelaçam e movimentamse circular e correlativamente, de forma que cada um deles, ao mesmo tempo em que ultrapassa o anterior, também o conserva. Conforme se mostrou nos exemplos acima, foi nesses momentos em que o estudo se concentrou, procurando delinear o instante de problematização.

Quando distração e dispersão são compreendidas como modos de atuar distintos um do outro, a distração não pode mais ser considerada indesejável para o processo de invenção. Entendida enquanto um movimento de suspensão ou uma ruptura do foco da atenção que poderá investir para além do foco e "deixar vir" o inesperado, aquilo que habitava a consciência num plano pré-reflexivo, ela se torna necessária para a experiência de um modo de atenção aberto à invenção. O movimento de suspensão do qual nos falam Crary (1999), Depraz e cols. (2003) instala-se justamente na ruptura cognitiva - "breakdown" de Varela (2003) -, esquivando-se da pressão da exterioridade.

Quando um breakdown acontece, deixamos o mundo conversar conosco, ou seja, experimentamos um momento estético. O breakdown vem acompanhado por dois movimentos: de focalização e de distração. De distração, porque ele nos força a sair do reconhecimento imediato e a experimentar outras forças que se acoplam e produzem, ao mesmo tempo, subjetivação e objetivação. Dá-se a invenção. A distração, como aqui é entendida, seria o fôlego da atenção: um momento de recuo necessário para que se possa viver uma experiência de si, que tem sido dispensada pelos modos de absorção produzidos pelo mundo midiático. A distração abre espaço para o que não é imediato, para o que permite o movimento do sujeito, sua experiência de duração. A distração, que é um dos aspectos da concentração, mostrase, então, como imanência da criação.

De acordo com Maturana e Varela (2002, p. 32), para entender a cognição, é preciso compreendê-la como um processo que ocorre necessariamente na "linguagem, que é nossa maneira particular de ser humanos e de estar no fazer humano". Nesse processo cognitivo, segundo Kastrup (1999), estão implicados dois momentos distintos, mas que se entrelaçam: um de problematização e outro de solução de problemas. Com base nessas afirmações, entendeu-se que a chave de análise dos acontecimentos deveria ser a observação dos atos comunicativos, através dos quais se poderia identificar os dois movimentos do processo cognitivo. Estes permitiriam observar os fluxos da atenção, que, por sua vez, se compõem de "atos descontínuos/linhas quebradas” (Bergson, 1999), ou colapsos (Varela, 2003). São movimentos de continuidade entre atenção e distração que, para poderem configurar um modo de concentração aberto, devem preservar um ponto de contato com o foco, que, no caso dessa pesquisa, somente pôde ser confirmado pela via do diálogo. Daí a necessidade de buscar contribuições no estudo e análise das conversações.

$\mathrm{Na}$ medida em que foi possível participar dessas dinâmicas de conversações, foi também possível encontrar modos de atuação característicos de cada um dos grupos observados. O modo como o breakdown foi acolhido, ou não, pela professora apontou para a necessidade de uma análise dos padrões de atuação e de dialogicidade. Esses padrões tornaram visíveis algumas características dos espaços escolares considerados propícios à aprendizagem de um modo de atenção aberto para a invenção.

Ao se revelarem os sinalizadores, o estudo e a busca se concentraram, então, em delinear as situações e experiências vividas que configuraram as práticas possibilitadoras da construção do espaço subjetivo que propiciaram tal experiência. Sendo assim, para a análise dos registros, após a identificação dos sinalizadores, surgiram as seguintes questões, que se tentou responder: $O$ que se passou nesse momento? Qual seu desdobramento? Como pode ser caracterizada a dinâmica de atuação que possibilitou o acolhimento do sinalizador? O que se passou no contexto em que a atenção se desdobrou em qualidade de encontro?

\section{Considerações Finais}

Aliando o percurso empreendido pelos estudos atuais da consciência, que vêm sublinhando o caráter heterogêneo e fluido da atenção, aos estudos vindos da Filosofia, da Psicologia, da Biologia e das Ciências Cognitivas, tem sido possível pensar na complexidade do processo atencional que revela seus diferentes modos de funcionamento. Esta pode ser concentrada ou dispersa, flutuante ou seletiva, involuntária ou voluntária, focalizada ou aberta, podendo, inclusive, combinar-se de muitas maneiras, como, por exemplo, concentrada e aberta ou ainda seletiva e focalizada, dentre outras.

Produzindo uma inflexão na certeza de que a atenção é necessária à aprendizagem, partiu-se da hipótese de que é possível a aprendizagem da atenção também no espaço escolar e que um modo de atenção concentrada e aberta, diversamente do modo dispersivo, tem estreita relação com a construção da capacidade humana para o pensamento e a criatividade.

No final de dois anos de investigação em sala de aula, a análise das observações levou-nos a sugerir que o ambiente deve ser criado e oferecido aos alunos por aqueles que ensinam, pois o modo atencional de uma pessoa advém de uma construção singular intra e intersubjetiva, ou seja, 
depende da história pessoal de cada um, vivida na interação com os outros.

Foi-se dando conta de que os mecanismos que criam espaços de aprender-subjetivar-se e que põem em movimento, no mesmo ato, atenção, aprendizagem e autoria de pensamento, precisam ser construídos desde um modo dialógico interacional de conversação, cujos efeitos se mostram além do ato de reconhecer. Sendo assim, acreditase que há uma relação de implicação entre o modo de atuar na sala de aula e a experiência de um modo de atender aberto à invenção.

O estudo dos protocolos selecionados, por revelarem breakdowns que resultaram em momentos divergentes à problematização, mostrou que a preocupação da professora com as respostas certas estava situada no reconhecimento do objeto da aprendizagem, o que resultava no empobrecimento do processo. Frequentemente surgia a pergunta: "Não estavas prestando atenção?", insinuando uma falta de atenção da criança, quando a falta de atenção parecia ser da professora em relação ao surgimento do inesperado e ao reconhecimento da capacidade pensante dos alunos.

Por outro lado, quando a professora adotava uma postura de incentivo ao diálogo, algo qualitativamente diferente do reconhecimento sempre se produzia. A análise das observações revelou que o cultivo de um modo de atuar comunicativo-dialógico-interacional está transversalizado pelo modo do professor compreender a aprendizagem e por seu modo de ser e experimentar o mundo. O estudo mostrou que, subjacente ao ato de ensinar, encontra-se uma epistemologia processual de construção do conhecimento, que implica numa compreensão da aprendizagem como um processo através do qual tanto o sujeito quanto o objeto se constroem.

Neste caso, o que se revelou interessante e fundamental para a pesquisa foi a capacidade da professora de se distrair da exigência de transmitir informação. O que significa dispor de uma atenção aberta, sem focalização específica, que lhe possibilitava captar tanto os enunciados, gestos e sinais que iam ao encontro do contexto, quanto também aquilo que parecia desconexo. Isto não implica falta de objetivo da professora, tampouco um relativismo absoluto que valoriza todas as formalizações e aceita todas as interpretações possíveis.

Nos exemplos em que o breakdown foi acolhido pela professora, sua capacidade de se distrair do foco atencional mostrou-se ao observador em diversas situações. Sua distração permitia-lhe encantar-se com o que as crianças revelavam. Tais revelações eram tomadas como um saber em construção e não como um déficit. Seu encantamento mostrava-se através do sorriso, do afeto e da surpresa seguida de um apelo ao ato de compartilhar a escuta, o pensamento e a fala.

Este estudo foi produzindo, ao longo do percurso, o desafio de encontrar práticas que viabilizassem o desencadeamento de um processo que não se esgotasse ao encontrar uma solução, mas que seguisse aberto ao surgimento do inesperado, acrescida ao exercício de se deixar afetar. Além da atenção concentrada e aberta, destaca-se, também, a capacidade da professora de encher de sentido o acontecimento. Ao iniciar o ano, via-se que o funcionamento da atenção de algumas crianças assumia características de dispersão, deslizando entre fatos e situações. A professora tratava, então, de ajudar a produzir sentido naquilo que parecia disperso. Em algumas cenas (como na cena do "computador", por exemplo), revelou-se uma capacidade para trazer de volta a atenção que rompe para outro lugar, sem aparente conexão com o contexto. A professora fazia um trabalho incansável de chamar de volta para a experiência, fazendo lembrar o trabalho de "tornarse consciente" da presença da mente na ação, a que se referem Varela, Thompson e Rosch (2003). Com isto, as crianças podiam experimentar aquilo que estavam fazendo, ou seja, podiam estar inteiramente na experiência. A arte da professora estava em encontrar o vínculo do que o aluno dizia com o que estava sendo discutido e, mais do que isto, propiciar espaço para que o aluno também o encontrasse. Esta atitude demonstrava um certo zelo, um cuidado com o outro, uma valorização e aceitação de um outro autor, revelando um certo tipo de relação com a aprendizagem perpassada pelo desejo de aprender com o aluno não um conteúdo, mas algo que diz do próprio aluno. Nesse espaço, tanto o aluno quanto o professor movimentam-se entre o lugar de quem está aprendendo e o lugar de quem está ensinando.

Algumas formas cognitivas são forjadas por nossos modos de atuar e resultam em subjetividade inventiva ou subjetividade recognitiva. Ambas foram encontradas durante a pesquisa e foi possível observar seus efeitos. $\mathrm{Na}$ atuação inventiva, para o exercício de problematização, a atenção requerida precisava poder distrair-se; já na atuação recognitiva, caracterizada pela tendência a tomar o mundo como oferecendo informações próprias para serem captadas, não se exigia mais do que uma atenção focalizada. A análise dos protocolos revela que as chances de cultivar uma atenção concentrada e aberta crescem muito quando o espaço pedagógico promove situações em que se exercita o pensar sobre o pensamento. Tal exercício mobiliza uma atenção aberta a experiências não recognitivas, de estranhamento, de problematização, novas e inédita, que atuam num plano de forças e não no plano da recognição.

Na sala de aula onde os breakdowns eram acolhidos, o exercício constante de prestar atenção ao ato mental revelado pela consiga "me interessa saber como vocês pensaram para descobrir" produzia momentos de reexperimentação da ação que era seguida mentalmente. Na cena das mãozinhas, todos - alunos e professora - seguiram juntos as hipóteses levantadas, repetindo, incansavelmente, as ações possíveis e refletindo sobre elas. Tratava-se de trazer para o cenário o que se produzia no ato de pensar. Ao fazer este trabalho, a cada nova cena, um novo detalhe ia sendo pensado, envolvendo a todos no trabalho de problematização.

Esta prática de trabalho com cenas revela, num espaço-tempo de uma manhã de aula, uma característica 
que se mostrou também num âmbito maior. Tal prática apresenta-se como uma possibilidade de romper com as amarras que prendem o processo de aprendizagem numa certa linearidade. Ensinar em cenas permite que cada atividade possa ser retomada a qualquer momento (no mesmo dia ou em outros), com outras configurações. A atividade mesma fica em suspenso: algo virá a seguir, mas não se sabe quando. Essa suspensão, sempre verbalizada, criava uma expectativa e com ela o desejo de retornar, transformando a busca do resultado em um trabalho circular e contínuo. Ao tratar a situação escolar dessa forma, um objeto de conhecimento não se mantém autônomo, mas em rede, engendrando-se uns nos outros e possibilitando que as crianças criem estratégias para um trabalho em permanente construção, ou seja, as crianças experimentam as possibilidades de alterar, reconstruir, mudar de ideia, acrescentar, rever, excluir algo que, no decorrer do tempo de espera, foi possível elaborar pensando. Trata-se de voltar a atenção não para o objeto, mas para o exercício do pensamento. Ao reiniciar uma tarefa, era preciso pensar no que já fora realizado e seguir pensando naquilo que se faria, evitando o automatismo e a reprodução e ativando o princípio de autonomia. Punha-se em jogo um legítimo trabalho de guardar-trazer de volta, que envolve consciência, memória e atenção.

Acredita-se que aprender um modo de atenção aberto à invenção requer um exercício consciente e constante, oferecido por um ambiente que acolhe o breakdown, prima pela comunicação dialógica interacional, possibilita a experiência de momentos estéticos e de produção de sentido para o que se diz e faz, promove práticas coletivas de pensar sobre o pensamento e propõe um trabalho permanente de construção-reconstrução do conhecimento. Tais experiências, marcadas pelo continuum esperar-esticar, fixar-romper, atender-desatender, se exercitadas quotidianamente, podem possibilitar uma atenção consciente, através da qual o aluno experimenta uma relação de intimidade consigo e com o objeto de conhecimento. Acontece um deslizamento, em que a aprendizagem da atenção revela-se numa atenção para si e para o mundo e não somente para o mundo.

Por fim, a pesquisa, ao se encontrar com algumas respostas, deparou-se com outras tantas perguntas que ficarão reverberando. Entretanto, como último comentário, cabe aqui ressaltar uma revelação: quanto mais a atenção daquele que ensina for concentrada e aberta, tanto mais criativas e problematizadoras serão as experiências dos alunos e igualmente maior será a frequência do surgimento de situações que possibilitem a construção de novos modos de atender, também mais concentrados e abertos. Tem-se, neste caso, um trabalho capaz de criar "novas modalidade de subjetivação do mesmo modo que um artista plástico cria novas formas a partir da palheta de que dispõe" (Guattari, 1992, p. 17).
Sendo assim, pode-se pensar que a aprendizagem de um modo de atenção aberta à invenção, na sala de aula, requer, além da competência exigida para o exercício da docência, um modo de experimentar o ato de ensinar e aprender que se desenvolve desde uma concepção de aprendizagem enquanto processo. É, também, uma questão de qualidade da atenção posta em atuação na atividade pedagógica, que implica a possibilidade de descentração. Acontece, então, um deslizamento, em que a aprendizagem da atenção revela-se numa atenção para si e para o mundo e não somente para o mundo. Assim, pensa-se que tanto o modo de atender aos alunos quanto o modo de compreender a aprendizagem se constroem em sintonia uma com a outra. Trata-se de uma construção sempre inacabada.

\section{Referências}

BERGSON, H. (1999). Matéria e memória: ensaio sobre a relação do corpo com o espírito. (2a ed.). São Paulo: Martins Fontes.

BERGSON, H. (2005). A evolução criadora. São Paulo: Martins Fontes.

COREA, C., \& LEWKOWICZ, I. (2005). Pedagogía del aburrido. Escuelas destituidas, familias perplejas. Buenos Aires: Paidós.

CRARY, J. (1999). Suspensions of perception: attention, spectacle, and modern culture. Cambridge, MA: MIT Press.

DEPRAZ, N., VARELA F. J., \& VERMERSCH, P. (2003). On becoming aware: a pragmatics of experiencing. Amsterdam: John Benjamins Publishing Company.

American Psychiatric Association. (1994). DSM-IV- Diagnostic and Statistical Manual of Mental Disorders (4a. ed.). Washington: Autor.

FERNÁNDEZ, A. (2001). Os idiomas do aprendente. Porto Alegre: Artmed.

GUATTARI, F. (1992). Caosmose: um novo paradigma estético. Rio de Janeiro: 34

KASTRUP, V. (1999). A invenção de si e do mundo: uma introdução do tempo e do coletivo no estudo da cognição. Campinas, SP: Papirus.

KASTRUP, V. (2004). A aprendizagem da atenção na cognição inventiva. Psicologia e Sociedade, 16(3), 7-16.

MATURANA, H. R., \& VARELA, F. J. (2002). De máquinas e seres vivos: autopoiese - a organização do vivo (3a ed.). Porto Alegre: Artmed.

SORDI, R. (1999). A comunicação professor-aluno: uma contribuição ao estudo sobre a construção do conhecimento. Tese de doutorado, Faculdade de Educação, Universidade Federal do Rio Grande do Sul, Porto Alegre.

VARELA, F. (2003). O reencantamento do concreto. Cadernos de subjetividade, 1(1), 72-86.

VARELA, F., THOMPSON, E., \& ROSCH, E. (2003). A mente incorporada: Ciências cognitivas e experiência humana. Porto Alegre: Artmed. 
Recebido em: 17/04/2008

Reformulado em: 03/07/2009

Aprovado em: 16/07/2009

\section{Sobre as Autoras}

Maria Helena De-Nardin

Mestre em Psicologia Social e Institucional pelo Programa de Pós-Graduação em Psicologia Social da UFRGS.

Regina Sordi

Professora adjunta do Instituto de Psicologia e do Programa de Pós-Graduação em Psicologia Social e Institucional da Universidade Federal do Rio Grande do Sul. 